\title{
Percepção do geoturismo por gestores de Parques
}

\author{
Perception of geotourism by Park managers
}

\section{Ricardo Eustáquio Fonseca Filho' 1}

\author{
Palavras-chave: \\ Turismo \\ Unidades de Conservação \\ Análise de Conteúdo
}

\begin{abstract}
Resumo:
A busca por recursos gera pressão antrópica sobre áreas naturais, essenciais para o balanço geoecossistêmico. Tais quais os parques, das categorias de unidades de conservação (UC's) mais buscadas pelos turistas, como o Parque Nacional da Serra do Cipó (PNSC) e o Parque Estadual do Itacolomi (PEIT) e o Parque Estadual da Serra do Rola-Moça (PESRM), MG e seus principais atrativos ecogeoturísticos, respectivamente cachoeiras, mirantes e pico. Por sua vez repercutindo na importância da gestão da UC tanto para a conservação quanto para o acesso ao turista. Assim, o objetivo do presente trabalho foi o de identificar a percepção do geoturismo pelos gestores de três parques mineiros. Para tanto, os procedimentos metodológicos considerados foram: revisão de literatura, elaboração de instrumento de coleta de dados, entrevistas dos gestores do PNSC, PEIT e PESRM, tabulação, análise do discurso e discussão dos dados. Os resultados demonstraram sobremaneira que: os gestores conhecem o geoturismo, mas conceituam sem o aspecto interpretativo; os parques têm atrativos geológicos, em parte motivação dos visitantes; o patrimônio geológico é relacionado à paisagem, sendo importante preservá-lo. Observou-se ainda a associação do geoturismo ao ecoturismo já presente nos parques, como estratégia de conservação da geodiversidade e da biodiversidade. Espera-se que a pesquisa sirva à revisão dos planos de manejo e gestão dos parques e possibilitem estratégias de geoconservação.
\end{abstract}

\begin{abstract}
The search for resources generates human pressure on natural areas, which are essential for the balance of the geo-ecosystem. Such as parks which, from the categories of nature protected areas, are the most sought after by tourists, as the Parque Nacional da Serra do Cipó, the Parque Estadual do Itacolomi, and the Parque Estadual da Serra do Rola-Moça, in Minas Gerais Brazil and their main eco-geotourism attractions, waterfalls, scenic viewpoints and peak respectively. In turn, this pressure reflects on the importance of the management of nature protected areas for both conservation and tourist access. Thus, the aim of the present work was to identify the perception of geotourism by the managers of three parks in Minas Gerais. For this, the
\end{abstract}

\footnotetext{
${ }^{1}$ Professor Adjunto do curso de bacharelado em Turismo e do Mestrado em Turismo e Patrimônio da Universidade Federal de Ouro Preto. ricardo.fonseca@ufop.edu.br
} 
methodological procedures considered were literature review, elaboration of a data collection instrument, interviews with the park managers, tabulation, analysis of the data discourse and discussion. Managers know geotourism, but they conceptualize it without the interpretative aspect; the parks have geological attractions, partly motivating visitors; the geological heritage is related to the landscape, and it is important to preserve it. The association between geotourism and ecotourism, already present in the parks, was also observed, as a strategy for the conservation of geodiversity and biodiversity. We expect that this research serves to the review of the management plans and to the management itself of the parks, enabling geoconservation strategies.

\section{INTRODUÇÃO}

A criação de áreas protegidas vem ocorrendo com um viés funcional, desde os primeiros jardins botânicos para fins de lazer e cura até os parques, destituindo populações tradicionais pela conservação cênica. A proteção desta beleza cênica pode garantir a conservação da biodiversidade de parte das paisagens, contribuindo ainda para o patrimônio cultural (VIEIRA; VERDUM, 2019). E cumprir um dos objetivos das unidades de conservação (UC's): de proteger as paisagens naturais e pouco alteradas de notável beleza cênica, pelos atributos naturais e culturais, a exemplo das categorias parque e monumento natural (BRASIL, 2000).

Para a Organização das Nações Unidas para a Educação, a Ciência e a Cultura (UNESCO, 2001) "Geoparques são áreas geográficas únicas e unificadas, onde os locais e as paisagens de significado internacional são gerenciados com um conceito holístico de proteção, educação e desenvolvimento sustentável.” Nesta linha, a respeito dos geoparques Onary-Alves et al. (2015, p. 104) afirmam que "compõem uma iniciativa de conservação e desenvolvimento científico, social e educacional de uma região de apelo cênico natural". No entanto, a gestão destas áreas é um desafio para todas esferas da sociedade. Se por um lado a responsabilidade de criação é do poder público, o uso público também o é pelo setor privado e pela sociedade civil privada.

Assim, nesta governança compartilhada, o volume de informações que os gestores têm que lidar (e.g. planos de manejo, programas de combate a incêndios florestais, projetos de pesquisa científica, autorizações de pavimentação e explotação mineral, dentre outros), somada à rotina administrativa (p.ex. controle de visitantes ) se mostra como uma ameaça, mas também como uma oportunidade.

Um exemplo é o geoturismo. Notadamente as pesquisas dessa área interdisciplinar do conhecimento (Ciências da Terra e Ciências Sociais Aplicadas) vêm crescendo, e UC's - em especial os parques e monumentos naturais têm sido objetos de estudo, valorizando a "desconhecida" geodiversidade. Embora presente em grande parte dos atrativos convencionais brasileiros (MANTESSO-NETO et al., 2012), como atrativo geoturístico, complementarmente à "conhecida" biodiversidade, por sua vez como atrativo ecoturístico. Quanto à geodiversidade, para Gray (2004) é a "variedade de ambientes, fenômenos e processos ativos de caráter geológico, geradores de paisagens, rochas, minerais, fosseis, solos e outros depósitos superficiais que constituem a base para vida na Terra".

Grande parte desses estudos geoturísticos foca no inventário e valoração da oferta dos chamados "geossítios", seguida (não necessariamente nesta ordem) de: gestão de geoparques (MEDEIROS; GOMES; NASCIMENTO, 2015), demanda geoturística, epistemologia do geoturismo (BENTO; FARIAS; NASCIMENTO, 2020; PEREIRA, 2017). No que tange ao Quadrilátero Ferrífero, Castro e Ruchkys (2017) observaram que cerca de $1 / 4$ das pesquisas na região são relacionadas ao geoturismo, demonstrando a importância de estudos relacionados à gestão do geoturismo em unidades de conservação.

Neste sentido, se buscou identificar a percepção do geoturismo pelos gestores de três parques de Minas Gerais (MG), localizados em importantes áreas geológicas do Brasil (Quadrilátero Ferrífero e Serra do Espinhaço), sendo eles: Parque Estadual do Itacolomi (PEIT), Parque Estadual da Serra do Rola-Moça (PESRM) e Parque Nacional da Serra do Cipó (PNSC). 


\section{Referencial teórico}

A Constituição Federal (BRASIL, 1988) destaca no Art. 225 a corresponsabilidade para sua gestão: "todos têm direito ao meio ambiente ecologicamente equilibrado, bem de uso comum do povo e essencial à sadia qualidade de vida, impondo-se ao Poder Público e à coletividade o dever de defendê-lo e preservá-lo para as presentes e futuras gerações". No caso das UC's o mesmo é ratificado pelo Art. $2^{\circ}$ da Lei do Sistema Nacional de Unidades de Conservação da Natureza - SNUC (BRASIL, 2000) que as considera como:

espaço territorial e seus recursos ambientais, incluindo as águas jurisdicionais, com características naturais relevantes, legalmente instituído pelo Poder Público, com objetivos de conservação e limites definidos, sob regime especial de administração, ao qual se aplicam garantias adequadas de proteção.

No entanto, o que se tem observado são gargalos diversos - em especial relacionados à gestão participativa -, dentre eles: questão fundiária, falta de recursos humanos, incêndios florestais (MMA, 2004). No que tange à categoria parques, o Art. 11 do SNUC esclarece seu objetivo básico:

a preservação de ecossistemas naturais de grande relevância ecológica e beleza cênica, possibilitando a realização de pesquisas científicas e o desenvolvimento de atividades de educação e interpretação ambiental, de recreação em contato com a natureza e de turismo ecológico (BRASIL, 2000).

A gestão das UC's tem sido objeto de estudos diversos (CARRERAS; DRUGUET, 1999; EAGLES; MCCOOL; HAYNES, 2002; CROFTS; GORDON, 2015; MEDEIROS; GOMES; NASCIMENTO, 2015; PELIZZARO et al., 2015). Não condicionada somente à área da administração, por envolver aspectos variados, a exemplo das três principais frentes, conforme metodologia de planos de manejo: recursos abióticos, bióticos e socioeconômicos. No entanto, desde os primórdios da proteção de áreas naturais, com os jardins botânicos na China até o modelo do Parque de Yellowstone nos Estados Unidos da América (EUA), há uma "orientação biocêntrica"

NASCIMENTO; SILVA, 2018).

(MEIRA;

Apesar da Carta de Digne, França, que, pouco antes da Rio-92, estabeleceu os direitos à Memória da Terra. De acordo com Munhoz e Lobo (2018, p. 28) "grande parte dos elementos da geodiversidade estão amparados na legislação brasileira", mas não há uma lei específica, podendo gerar diferenças na interpretação e, consequentemente, na geoconservação. Para Sharples (2002) a geoconservação busca preservar a diversidade natural do substrato (processos geológicos), formas (processos geomorfológicos) e solo (processos pedológicos), via processos naturais dos mesmos.

A percepção, por sua vez. envolve características como informação, conhecimento, representação social, entre outros. Ou seja, a relação do ser humano com o meio, trazendo à tona a "percepção ambiental", em outras palavras, que "a natureza é aquilo que observamos pela percepção obtida através dos sentidos" (WHITEHEAD, 1920, p. 5).

Neste sentido, estudos de efetividade de gestão têm sido realizados em UC's estaduais de Minas Gerais (LIMA; RIBEIRO; GONÇALVES, 2005; REZENDE et al., 2010; SANTOS, 2016) e federais (WWF, 2017) com vistas a, dentre outros, UC's - como os parques - não serem "de papel". De forma a existirem além do decreto criador, como espaço gerido e usufruído pela comunidade e se conservando seu patrimônio natural e cultural, a exemplo do ecoturismo

Embora não haja um consenso que o geoturismo seja um segmento turístico (COUTINHO et al., 2019; MOREIRA, 2010), o presente trabalho considera o mesmo como em desenvolvimento, que será possível a partir da definição de sua oferta, demanda, espaço geográfico e distribuição. Aspectos do mercado turístico estes prementes nos olhares dos gestores. Embora suas raízes remontam aos trabalhos de campo de Geografia Física no século XVII (HOSE, 2016) ou de Geologia no séc. XIX (MACFARLANE, 2005 apud MOREIRA, 2010 , p. 6), a primeira vez que o termo foi conceituado se deve a Hose (1995, p. 17) como sendo a "provisão de serviços e facilidades interpretativas no sentido de possibilitar aos turistas a compreensão e aquisição de conhecimentos de um sítio geológico e geomorfológico ao invés da simples apreciação estética". Um parêntese com a visão oriental, conforme Chen, Lu e Ng (2015, p. xiii), que afirmam que o geoturismo é conhecido na China como "Turismo de Ciências da Terra". O mesmo se dá por meio de: "Geólogos chineses têm 
adotado métodos geocientíficos na exploração de oportunidades turísticas fornecidas pela geologia e pela paisagem natural". O que não difere muito da visão ocidental, ambas aproximando de princípios do ecoturismo.

Para o termo ecoturismo tampouco há um consenso, embora Buckley (2003, p. 76) esclareça sua ligação com o geoturismo:

O ecoturismo pode, portanto, ser visto como geoturismo com um resultado triplo positivo. Existem várias vantagens nessa aproximação. (1) Ele esclarece o significado de ecoturismo sem redefini-lo. (2) Ele ignora os componentes de serviço que são comuns ao turismo em geral, não distinto do ecoturismo. (3) Trata a gestão do meio ambiente e interpretação como meios, não fins. (4) Requer uma contabilidade precisa dos custos e benefícios ambientais e sociais, bem como financeiros. (5) Isso diferencia o ecoturismo de produtos turísticos com um mero verniz de verde. (6) Os produtos e organizações de turismo que geralmente são vistos como as melhores práticas do mundo em ecoturismo estão de acordo com esta definição.

A gestão do ecoturismo é abordada por pesquisadores há longa data, ao contrário da gestão do geoturismo, que muitas vezes é associada à gestão de geoparques (FARSANI; COELHO; COSTA, 2010; MEDEIROS et al., 2015), desassociada da gestão em UC's (MEIRA; NASCIMENTO; SILVA, 2018). Gargalo este buscado pelo presente estudo, que em seguida caracterizará a amostra selecionada para melhor discussão da percepção dos gestores para o geoturismo.

\section{Descrição da área de estudo}

Criado em 1984, o PNSC (Figura 1) tem cerca de 31.000 ha, situa-se nos municípios Jaboticatubas, Santana do Riacho, Morro do Pilar e Itambé do Mato Dentro (MG) e é gerido pelo Instituto Chico Mendes de Conservação da Biodiversidade (ICMBIO, 2009). Seus principais atrativos são cachoeiras e trilhas, formados em sua maioria pela Serra do Espinhaço (Figura 2A).

O PESRM, criado em 1994, tem 3.942 ha e está localizado nos municípios de Belo Horizonte, Brumadinho, Ibirité e Nova Lima (MG) (Figura 1) e é gerido pelo IEF e pela Companhia de Saneamento de Minas Gerais (COPASA). Seus principais atrativos são os mirantes, em especial o do Morro dos Veados, sustentado pela canga da serra da Moeda (Figura 2B) (IEF, 2007b).

E o PEIT foi criado em 1967, possui 7.543 hectares (ha) e está localizado nos municípios de Ouro Preto e Mariana (MG) (Figura 1), sendo gerido pelo Instituto Estadual de Florestas (IEF, 2007a). Seu principal atrativo é o Pico do Itacolomi, ponto mais alto do município de Mariana, com 1.772 metros de altitude (Figura 2C).

Devido à sua fisiografia os parques têm rica biodiversidade (DRUMMOND et al., 2005) e geodiversidade (MACHADO; SILVA, 2010), se constituindo, em sua maior parte, por: vegetação de Mata Atlântica e Cerrado, com espécies endêmicas dos campos rupestres quartzíticos (PEIT e PNSC) e ferruginoso (PESRM); rica hidrografia das Bacias Hidrográficas do Rio São Francisco (PESRM e PNSC) e do Rio Doce ( PEIT em ambas); geomorfologia com relevo predominantemente montanhoso (PEIT), com vales (PNSC) e platôs (PESRM); solos jovens, minerais e pouco desenvolvidos nos três parques (IEF, 2007a; IEF, 2007b; ICMBIO, 2009).

Quanto à geologia, fazem parte de importante compartimento brasileiro: o Quadrilátero Ferrífero e a Serra do Espinhaço. Em geral o PEIT e o PNSC são formados por rochas quartzíticas do período Proterozóico, Grupos Sabará e Macaúbas respectivamente. Quanto ao PESRM destaca-se o Grupo Itabira, com formações ferríferas, dentre elas a canga (BRITO, 2017). O regime de dobras e falhas à qual a região dos parques foi condicionada ao longo da história geológica influenciou por um lado o viés econômico, com a presença de reservas minerais, e por outro o viés ambiental, com paisagens e espécies da biodiversidade e geodiversidade únicas.

De acordo com ICMBIO (2009):

nenhum atributo caracteriza melhor a Serra do Cipó do que a sua diversidade. Começando por sua geologia, cuja história remonta a 1.700 milhões de anos, com uma grande variedade de rochas calcárias, quartzitos, granitos e variedades de solos. Toda essa variedade geológica teve origem na deposição de material marinho que foi, ao longo do tempo, sendo sedimentado no fundo de um oceano. O relevo acidentado oferece tantos caminhos aos córregos que brotam de todo lugar, culminando nas diferenças climáticas entre as vertentes leste e a oeste. Toda esta base posta à disposição da evolução culminou em uma das floras mais diversas do planeta, com um altíssimo grau de endemismo, um dos maiores do mundo, e com mais de 1700 espécies já registrada. 
Figura 1 - Mapa de localização e acesso do Parques Nacional da Serra do Cipó, Parque Estadual da Serra do Rola Moça e Parque Estadual do Itacolomi (MG).



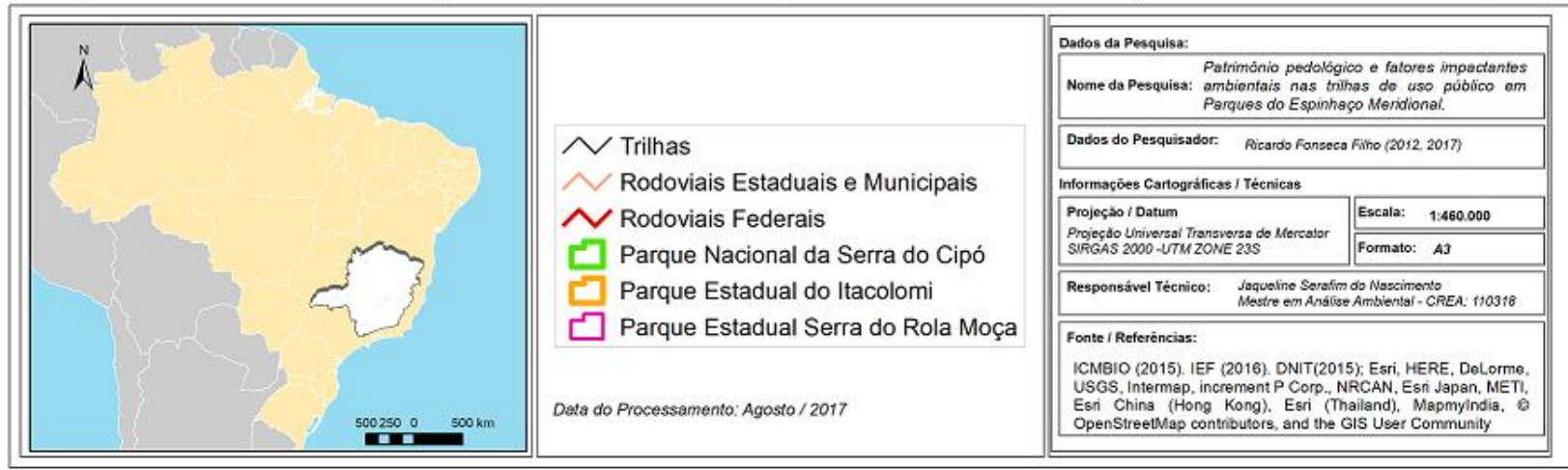

Fonte: autor (2017). 
Figura 2 - A - Serra do Cipó. B - Serra do Rola-. C - Pico do Itacolomi.

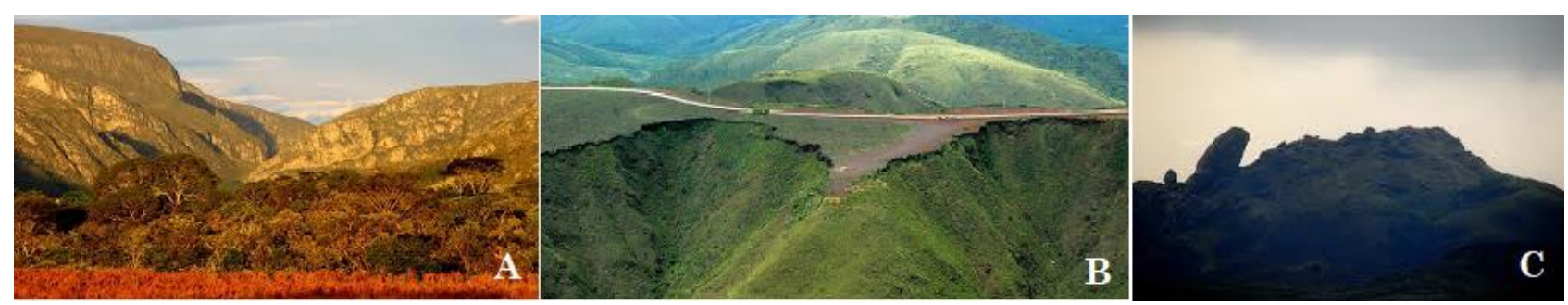

Fonte: A - B - Edward E. Jr. (sd, 2014) ; C - Evandro Rodney (sd).

Abordando a geodiversidade do PEIT, Ostanello, Danderfer e Castro (2013, p. 287) afirmam que "Dentre os componentes da geodiversidade local encontram-se afloramentos ruiniformes, feições estruturais bem preservadas, grutas, cachoeiras, fendas, além de uma exuberante paisagem."

Conforme Reis (2017, p. 132) o PESRM tem "geodiversidade alta pertencem às feições de Domínios montanhosos e Escarpas serranas, que estão associadas a grande presença das classes de variáveis altitude e solos", em especial devido a ocorrências minerais (PEREIRA; AZEVEDO; ONDICOL, 2013), como os campos rupestres ferruginosos.

Quanto aos serviços, contam com monitores ambientais, brigadas de combate a incêndio, pesquisas científicas, projetos de educação ambiental com escolas das comunidades em que se inserem, conselhos consultivos, entre outros.

\section{METODOLOGIA}

A pesquisa se dividiu em duas etapas: de escritório e de campo. Na primeira houve revisão bibliográfica e digital voltada à área de estudo (planos de manejo dos Parques) e temáticas afins (geoturismo, efetividade de gestão e análise de conteúdo). Em seguida elaborou-se instrumento de coleta de dados do tipo roteiro estruturado qualitativo, conforme metodologia survey (BABBIE, 2003).

$\mathrm{O}$ roteiro estruturado quali-quantitativo, composto com nove perguntas buscou compreender duas categorias: visitante e geoconservação - geologia e solos. As variáveis utilizadas são afins aos roteiros de entrevista a geoturistas do PEIT (FONSECA FILHO; MOREIRA, 2017), PESRM (FONSECA FILHO; RIBEIRO, 2016) e PNSC (FONSECA FILHO et al., 2018) e têm importância devido à relação com a gestão do geoturismo, pois compreendendo-se a percepção dos gestores quanto a informações relacionadas ao geoturismo pode-se compreender planejamento e ações da gestão do geoturismo nos parques.

A amostra se constituiu dos gestores das UC's, sendo duas entrevistas pessoais com gravação de áudio no aparelho modelo Sony ICD-PX240. Todos entrevistados autorizaram a gravação da entrevista e a utilização dos dados por meio de Termo de Consentimento e Livre Esclarecido. As entrevistas, em seguida, foram transcritas no software Microsoft Office Word e, em seguida, houve tabulação dos dados no Microsoft Office Excel.

$\mathrm{Na}$ etapa de campo, inicialmente, submeteuse projetos de pesquisa às instituições gestoras dos Parques, sendo autorizadas as licenças de pesquisa IEF 23/2013 e 24/2013, e SISBIO $38592-1$, todas renovadas anualmente. Em sequência foi agendada entrevista do tipo domiciliar com os três gestores, sendo realizadas entre o fim de 2016 e o início de 2017: duas presenciais no Centro de Visitantes (uma no PEIT e uma no PESRM); e uma remota via Google Forms ao chefe do PNSC.

Após a tabulação dos dados os mesmos foram submetidos à análise de conteúdo, que, segundo levantamento de Sousa, Rodrigues e Tomazzoni (2016), é relevante na área do turismo. De acordo com Bardin (1999, p. 44), análise de conteúdo é

um conjunto de técnicas de análise das comunicações visando obter por procedimentos sistemáticos e objetivos de descrição do conteúdo das mensagens indicadores (quantitativos ou não) que permitam a inferência de conhecimentos relativos às condições de produção/recepção (variáveis inferidas) destas mensagens.

\section{RESULTADOS}

O código e suporte linguístico das entrevistas foi basicamente oral, e somente um entrevistado por escrito. 
A categoria visitante, ou seja, quem é o usuário dos parques, traz dados do ponto de vista dos gestores (Quadro 1), tais como: a maioria é da comunidade e excursionistas (PEIT e PESRM); viajam com famílias, tem acesso à informação pela internet (redes sociais) e "boca a boca"; e têm como motivação ecoturismo (paisagem) e turismo de aventura (caminhada e cicloturismo em trilhas). Dados que ratificam levantamentos do Observatório de Turismo de Minas Gerais (2017) para Ouro Preto, Brumadinho e Santana do Riacho, municípios onde estão as principais áreas visitadas dos parques.

Quadro 1. Análise de conteúdo das entrevistas aos gestores dos Parques.

\begin{tabular}{|c|c|c|c|}
\hline Categoria & Subcategoria & Unidade de registro & Unidade de contexto \\
\hline \multirow{3}{*}{ 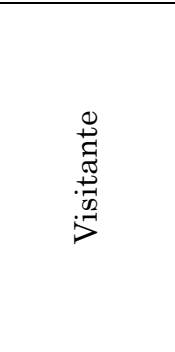 } & \multirow{3}{*}{$\begin{array}{l}\text { Informação } \\
\text { visitante }\end{array}$} & $\begin{array}{l}\text { TripAdvisor, Facebook, } \\
\text { Parques de Minas e "boca a } \\
\text { boca" (PEIT) }\end{array}$ & $\begin{array}{l}\text { O retrato atual: eu acho que o Facebook (...), o } \\
\text { parque ele é indicado no TripAdvisor (...), mas eu } \\
\text { acho que é o principal, e o boca a boca (PEIT) }\end{array}$ \\
\hline & & $\begin{array}{l}\text { Televisão, redes sociais e } \\
\text { "boca a boca" (PESRM) }\end{array}$ & $\begin{array}{l}\text { Própria mídia televisiva, pelos programas que } \\
\text { eles vinculam, que pegam um público muito } \\
\text { grande né [sic] e depois as redes sociais e o "boca } \\
\text { a boca” (PESRM) }\end{array}$ \\
\hline & & $\begin{array}{l}\text { Internet e reportagens TV } \\
\text { e jornais (PNSC) }\end{array}$ & $\begin{array}{l}\text { Internet e reportagens na midia (TV, jornais) } \\
(P N S C)\end{array}$ \\
\hline \multirow{13}{*}{ 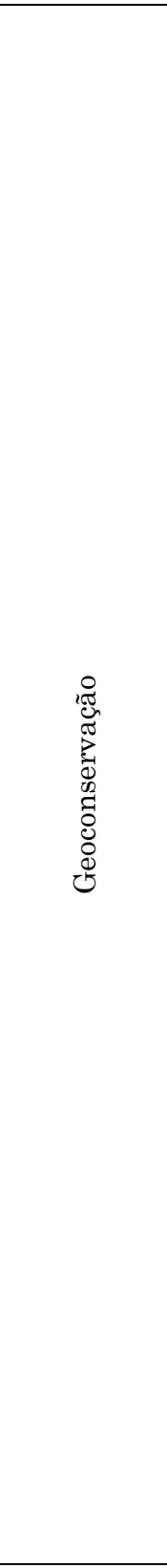 } & \multirow{3}{*}{$\begin{array}{l}\text { Disponibilidade } \\
\text { conhecimento } \\
\text { geologia } \\
\text { visitante }\end{array}$} & Não (PEIT) & $\begin{array}{l}\text { Se ele tiver que ir no centro de visitantes, e na } \\
\text { parte onde houve uma sinalização interpretativa } \\
\text { com esse fim, ele vai ter essas informações né } \\
\text { [sic]? Talvez pra [sic] quem não é da área, não } \\
\text { tem nenhum conhecimento é um pouco difícil } \\
\text { entender (PEIT) }\end{array}$ \\
\hline & & Em parte (PESRM) & $\begin{array}{l}\dot{E} . . . \text { Bom (...) nós gostaríamos mais que ele } \\
\text { tivesse conhecimento (PESRM) }\end{array}$ \\
\hline & & Não (PNSC) & Não $(P N S C)$ \\
\hline & \multirow{3}{*}{$\begin{array}{l}\text { Contribuição } \\
\text { conhecimento } \\
\text { geologia para } \\
\text { paisagem }\end{array}$} & Sim (PEIT) & É claro, certamente (PEIT) \\
\hline & & Sim (PESRM) & $\begin{array}{l}\text { Com certeza, com certeza, a Serra do Rola-Moça, } \\
\text { a Serra da Calçada, a Serra da Moeda, a Serra } \\
\text { do Curral, isso é um referencial que o visitante } \\
\text { tem (PESRM) }\end{array}$ \\
\hline & & $\operatorname{Sim}(\mathrm{PNSC})$ & $\operatorname{Sim}(P N S C)$ \\
\hline & \multirow{3}{*}{$\begin{array}{l}\text { Definição } \\
\text { Patrimônio } \\
\text { Geológico }\end{array}$} & $\begin{array}{l}\text { Arcabouço paisagem } \\
\text { envolvendo área protegida } \\
\text { (PEIT) }\end{array}$ & $\begin{array}{l}\text { É todo esse arcabouço da paisagem que tá } \\
\text { envolvendo a área protegida, do qual ela faz } \\
\text { parte(...) A qual o visitante vai poder ver, vai } \\
\text { poder tocar e interagir (...) que carece de } \\
\text { preservação, porque há uma fragilidade (PEIT) }\end{array}$ \\
\hline & & Relevo (PESRM) & $\begin{array}{l}\text { Na realidade a paisagem de um modo geral ela } \\
\text { tá associada à geologia né? (PESRM) }\end{array}$ \\
\hline & & $\begin{array}{l}\text { Formações geológicas, } \\
\text { solos, rochas, fósseis, } \\
\text { cavidades (PNSC) }\end{array}$ & $\begin{array}{l}\text { O conjunto das formações geológicas, } \\
\text { testemunhos dessas formações, diversidade de } \\
\text { solos e rochas, fósseis, cavernas (PNSC) }\end{array}$ \\
\hline & \multirow{3}{*}{$\begin{array}{l}\text { Importância } \\
\text { proteção } \\
\text { patrimônio } \\
\text { geológico }\end{array}$} & $\begin{array}{l}\text { Visitantes e geossistema } \\
\text { (PEIT) }\end{array}$ & $\begin{array}{l}\text { Tem dois vieses: primeiro pela importância } \\
\text { paisagística, cultural, do próprio visitante, pra } \\
\text { [sic] gente assegurar isso pras [sic] futuras } \\
\text { gerações, e segundo pra [sic] preservação de } \\
\text { processos geossistêmicos como um todo (PEIT) }\end{array}$ \\
\hline & & $\begin{array}{l}\text { Preservar a paisagem } \\
\text { (PESRM) }\end{array}$ & $\begin{array}{l}\text { Ela é muito importante, ela é fundamental para a } \\
\text { existência do próprio parque, a proteção até por } \\
\text { causa das minerações (PESRM) }\end{array}$ \\
\hline & & $\begin{array}{l}\text { Proteção ambiente, } \\
\text { conhecimento científico } \\
\text { (pesquisa), EA, emprego e } \\
\text { renda (turismo) (PNSC) }\end{array}$ & $\begin{array}{l}\text { E parte da proteção ao ambiente; proporciona } \\
\text { conhecimento e educação ambiental; na } \\
\text { perspectiva do turismo, é fator gerador de } \\
\text { emprego e renda; importante para a pesquisa e } \\
\text { desenvolvimento científico (PNSC) }\end{array}$ \\
\hline & & $\begin{array}{l}\text { Erosão e assoreamento } \\
\text { (PEIT) }\end{array}$ & $\begin{array}{l}\text { Eu acho que desinteressa ao cara quando ele vê o } \\
\text { ambiente detonado assim. Ou um poço de uma } \\
\text { cachoeirinha assim... (PEIT) }\end{array}$ \\
\hline
\end{tabular}




\begin{tabular}{|c|c|c|}
\hline \multirow[b]{2}{*}{$\begin{array}{l}\text { Motivo } \\
\text { modificação } \\
\text { paisagem }\end{array}$} & $\begin{array}{l}\text { Descaracteriza o relevo } \\
\text { (PESRM) }\end{array}$ & $\begin{array}{l}\text { Por causa do uso (...), a sua utilização, a } \\
\text { mineração vai descaracterizar, vai mudar o } \\
\text { relevo, a geologia da região (PESRM) }\end{array}$ \\
\hline & $\begin{array}{l}\text { Flora, fauna, feições da } \\
\text { paisagem (PNSC) }\end{array}$ & $\begin{array}{l}\text { Há reflexos diretos dessa degradação sobre a } \\
\text { flora, consequentemente sobre a fauna; a base da } \\
\text { paisagem e suas feições estão assentadas no solo e } \\
\text { nas formações rochosas, a degradação destes } \\
\text { modifica diretamente as feições da paisagem } \\
\text { (PNSC) }\end{array}$ \\
\hline \multirow{3}{*}{$\begin{array}{l}\text { Exemplos } \\
\text { atrativos } \\
\text { geológicos } \\
\text { Parque }\end{array}$} & Pico do Itacolomi (PEIT) & $\begin{array}{l}\text { Eu acho que eu não vou conseguir nem responder } \\
\text { essa pergunta (...), por eu estar aqui há um ano e } \\
\text { meio, por eu focar mais na parte gerencial eu } \\
\text { pouco conheci o Itacolomi. É... muitas áreas o } \\
\text { acesso é difícil (...). Já fui ao Pico, obviamente, } \\
\text { sobrevoei, mas eu não sei, ainda tem muito lugar } \\
\text { que eu quero conhecer, que eu acho que vai me } \\
\text { surpreender (...) (PEIT) }\end{array}$ \\
\hline & $\begin{array}{l}\text { Mirantes (Morro dos } \\
\text { Veados, dos Planetas, } \\
\text { Jatobá), cavidades, canga } \\
\text { (PESRM) }\end{array}$ & $\begin{array}{l}\text { Ah [sic]! Mais de um! É a própria paisagem, as } \\
\text { grutas, as cavernas, os mirantes...Eu acho uma } \\
\text { coisa que é bem relacionada a isso é a canga. A } \\
\text { canga é uma coisa que caracteriza muito a região. } \\
\text { Inclusive é muito usada. O próprio centro de } \\
\text { visitantes, que a sede administrativa, ela explora } \\
\text { essa coisa da paisagem, do relevo, até porque } \\
\text { para ter harmonia (PESRM) }\end{array}$ \\
\hline & $\begin{array}{l}\text { Serra (do Cipó), Cânion } \\
\text { (das Bandeirinhas), } \\
\text { Formações rochosas } \\
\text { (quartzito) (PNSC) }\end{array}$ & $\begin{array}{l}\text { Formações serranas, Travessão, Cânion das } \\
\text { Bandeirinhas, formações rochosas (em quartzito). } \\
\text { (PNSC) }\end{array}$ \\
\hline \multirow{3}{*}{$\begin{array}{l}\text { Definição } \\
\text { Geoparque }\end{array}$} & $\begin{array}{l}\text { Territórios de interesse } \\
\text { geológico para conservação } \\
\text { e divulgação (PEIT) }\end{array}$ & $\begin{array}{l}\text { São territórios de interesse geológico, pra [sic] } \\
\text { preservação, conservação e divulgação (...) é um } \\
\text { programa, com reconhecimento da Unesco (...) } \\
\text { igual à Reserva da Biosfera (PEIT) }\end{array}$ \\
\hline & $\begin{array}{l}\text { Espaço territorial } \\
\text { associado ao relevo e } \\
\text { geologia (PESRM) }\end{array}$ & $\begin{array}{l}\text { Um espaço territorial, que tá [sic] associado ao } \\
\text { relevo e à geologia, como o Quadrilátero Ferrífero } \\
\text { (...) envolve biomas diferentes, é... mas ele tá [sic] } \\
\text { numa formação geológica que...na sua concepção } \\
\text { você possa ter um... direcionamento de gestão } \\
\text { (PESRM) }\end{array}$ \\
\hline & Não respondeu (PNSC) & Não respondeu (PNSC) \\
\hline \multirow{3}{*}{$\begin{array}{l}\text { Benefícios } \\
\text { visitantes } \\
\text { Geoparque }\end{array}$} & Em parte (PEIT) & $\begin{array}{l}\text { Pode com ressalvas (...) desde que haja } \\
\text { instrumentos, programas (...) gestão participativa } \\
\text { principalmente (PEIT) }\end{array}$ \\
\hline & $\begin{array}{l}\text { Experiência, proteção } \\
\text { (PESRM) }\end{array}$ & $\begin{array}{l}\text { Hoje a gente tem um foco ou direcionamento das } \\
\text { pessoas em... momentos, lugares únicos (...). } \\
\text { Então a partir do momento, é como se fosse um } \\
\text { colecionador, assim é a satisfação pelo estar } \\
\text { desfrutando de uma área que... é reconhecida } \\
\text { como um geoparque (PESRM) }\end{array}$ \\
\hline & $\begin{array}{l}\text { Educação ambiental, } \\
\text { emprego e renda, } \\
\text { participação comunidade } \\
\text { (PNSC) }\end{array}$ & $\begin{array}{l}\text { Associando a visitação a uma estratégia de } \\
\text { educação ambiental, os visitantes podem se } \\
\text { tornar aliados da causa da visitação; com a } \\
\text { geração de emprego e renda associada à } \\
\text { atividade turística, que pode beneficiar as } \\
\text { comunidades locais; justificando a maior } \\
\text { aplicação de recursos na conservação (PNSC) }\end{array}$ \\
\hline
\end{tabular}

Organização: autor (2020).

Quanto às falas dos gestores acerca dos atrativos visitados há uma conotação ao geoturismo, por envolver valores culturais e naturais: ele vai no Pico ou na Lagoa, ele vai parar aqui, visita ao centro de visitantes (...). Assim, com certeza, entre todos é o mais visitado, porque ele vai parar aqui, ele vai 
fazer o "tour" dele aqui no centro histórico e depois ele vai partir para seu destino final. (GESTOR PEIT, 2017)

Agora o que a gente tem é o mirante do Morro dos Veados que é o mais conhecido, é o mais visitado, realmente ele tem uma visitação muito grande. (GESTOR PESRM, 2016)

Embora não houve resposta do gestor do PNSC, o Cardápio de Atrativos (ICMBIO, 2020) do parque demonstra a água (em especial a Cachoeira da Farofa e o Cânion das Bandeirinhas), são os principais atrativos. Os gestores também têm uma percepção da motivação dos visitantes similar àqueles atrativos visitados, geoecoturísticos:

É o Pico do Itacolomi, sem dúvida, é o atrativo carro-chefe. (GESTOR PEIT, 2017) A paisagem (...) os mirantes. (GESTOR PESRM, 2016)

Conhecer as cachoeiras no Parque. (GESTOR PNSC, 2017)

Por sua vez, quanto às trilhas em UC's e geoparques são o principal meio de se alcançar os atrativos. Segundo respostas dos entrevistados (Quadro 1) as características das mesmas nos parques são predominantemente positivas, com destaque para a necessidade de criação de trilhas geointerpretativas.

Eisenlohr et al. (2013) apontaram em revisão de publicações que as trilhas têm um papel ecológico para a manutenção dos ecossistemas, incluindo para a geodiversidade, além da biodiversidade. Motivo pelo qual são objeto de estudo também da gestão dos parques amostrados, vide planos de manejo, roteiros geoturísticos propostos (FONSECA FILHO; CASTRO; VARAJÃO., 2019; OSTANELLO; DANDERFER; CASTRO, 2013) e depoimentos dos gestores, que consideram importante a melhoria das mesmas, em especial enquanto acesso aos atrativos e impactos como erosão e lixo - temática esta recorrente em pesquisas geoturísticas e ecoturísticas em parques.

$\mathrm{E}$ por fim, quanto à categoria geoconservação, devido à quantidade de dados se optou por focar nos atrativos visitados, quais são os considerados geológicos, definição de geoturismo e olhar dos geoparques.

Quanto ao geoturismo, os entrevistados sabem o que é ou já ouviram falar a respeito, no entanto, as definições do conceito pelos gestores variam. Enquanto para os gestores do PEIT e do PNSC inclui princípios do geoturismo, como a interpretação da geodiversidade, para o do
PESRM traz também aspectos do ecoturismo:

a pessoa ter oportunidade de interpretar a paisagem que ela está inserida, é ela ter a oportunidade de decodificar a história não só do local, mas da própria vida da Terra que tá impressa naquelas rochas, impressa naquela paisagem, é ela ter oportunidade de aprender com a Geologia, que é uma ciência sobre os processos naturais e como que nós homens a gente pode interferir nesses processos. (GESTOR PEIT, 2017)

o geoturismo está associado a essa paisagem (...) um conceito novo de você está associando ao relevo (...) relacionado à biodiversidade, à fitofisionomia da região, se é mata atlântica (...) (GESTOR PESRM, 2016)

Modalidade de turismo que tem como referência a visitação centrada no patrimônio geológico, que busca conhecer e divulgar aspectos da formação geológica/geomorfológica. (GESTOR PNSC, 2017)

Esta observação do gestor do PNSC - da relação com o patrimônio geológico e o conhecimento a respeito do mesmo - é corroborada por Newsome, Dowling e Leung (2012), que analisaram dois destinos geoturísticos em Taiwan e na Austrália e constataram que, mesmo com o manejo de geossítios e geoparque, impactos negativos são difíceis de conter, o que justifica sobremaneira a proteção. $O$ que não difere do ecoturismo, conforme apontado por Buckley, Pickering e Weaver (2003) e pela fala dos gestores do PEIT e do PESRM, ao perceberem que a conservação pelo geoturismo pode ser dar pela educação (ambiental), tal qual no ecoturismo:

Partindo do pressuposto que a gente pode educar as pessoas. (GESTOR PEIT, 2017) (...) mais uma opção para a visitação (...) associada à educação ambiental. (GESTOR PNSC, 2017)

Quanto ao patrimônio geológico, os gestores levantaram características relacionadas ao mesmo, no entanto somente o gestor do PEIT apontou duas essenciais: proteção e fragilidade. De acordo com Brilha (2005) são elementos singulares da geodiversidade importantes para o entendimento da evolução da Terra e que precisam ser conservados. O que é ratificado ainda pelos olhares de Carreras e Druguet (1999) quanto à relação com o patrimônio cultural, por exemplo, saberes e fazeres da 
mineração e da construção.

Questionados se o patrimônio (geológico) pode auxiliar na conservação das UC's os gestores focam nos valores funcionais (PEIT), estético (PESRM) e educacional (PNSC). No caso deste último parque, Brito (2017, p. 30) constatou que há geoconservação no Plano de Manejo do PNSC, "embora na prática, não fora identificado uma ação que constitua uma proposta efetiva de manejo neste aspecto", inclusive de educação ambiental, que não são contínuas. Pesquisa estadual de Alves et al. (2011, p. 355) com 74 UC's estaduais de MG sendo 26 parques, incluindo o PEIT e o PESRM - caracterizou que é "evidente, portanto, que os avanços que o IEF vem conseguindo em vários aspectos relacionados à gestão dos recursos naturais mineiros devem ser estendidos aos gerentes das UC de maneira mais efetiva." Quanto à formação dos gerentes das UC's mineiras os autores (ALVES et al., 2011) destaca Biólogos, coincidindo com a formação dos três gestores dos parques amostrados na presente pesquisa.

Em estudo nacional, no Parque do Bicão, em São Carlos - SP, Toyama et al. (2018) reconheceram a importância do parque urbano para a geoconservação por meio do levantamento de suas informações geológicas. Conforme Reis (2017, p. 133) “o PESRM é uma importante unidade de conservação do Quadrilátero Ferrífero e seu planejamento e gestão devem considerar ações que valorizem sua geodiversidade por meio da educação ambiental como é o caso do geoturismo."

Já estudos internacionais, como Crofts e Gordon (2015), observaram que a geoconservação em áreas protegidas é necessária em função das ameaças e pressões como urbanização, mineração, mudanças climáticas e, inclusive, o geoturismo. Por sua vez, Gordon et al. (2018) corroboram ao identificar seis áreas-chave que oferecem oportunidades para melhorar a geoconservação, dentre elas a gestão de áreas protegidas, o que vem ao encontro da presente pesquisa.

Quanto à percepção do geoparque, confundido por parte considerável dos (geo)turistas dos parques - citados anteriormente - como "parque geológico" e o Quadrilátero Ferrífero à "mineração de minério de ferro", os gestores conhecem que os parques PEIT e PESRM estão inclusos e o PNSC está próximo. Considerando que a maioria das pesquisas científicas em UC's se relacionam à biodiversidade (em especial a flora), Świerkosz et al. (2017) observaram a relação da geoconservação com a educação em geociências na conservação da biodiversidade em um Geopark na Polônia, o que aponta para esta abordagem integradora, tanto pelos gestores dos parques, quanto pelas instituições gestoras (IEF e ICMBIO).

Reynard e Brilha (2018) trazem alguns exemplos de gestão do patrimônio geológico, como na Tasmânia (Austrália) e Monumento Nacional Florissant Fossil Beds (EUA), destacando a importância de um movimento de proteção a partir das comunidades locais, e não somente de órgãos públicos. Esta questão se apresenta na pesquisa a partir das respostas dos entrevistados quanto à gestão (boa) e participação da comunidade (razoável).

Observa-se que há certa infraestrutura (e.g. centro de visitantes e trilhas) e serviços (e.g. monitores e pesquisas) para a geoconservação nos parques. Ferreira, Lima e Candeiro (2020, p. 598) trazem uma discussão interessante a partir de estudo em Paraúna (GO), ao relacionarem a estrutura e a visitação à conservação, trazendo subsídios para gestores de áreas protegidas ou não:

Cada sítio da Geodiversidade tem sua especificidade com diferentes elementos naturais como cachoeiras, morros, paredes de pedra e cavernas. Por serem pontos turísticos, essas áreas são visitadas periodicamente, porém, algumas localidades carecem de infraestrutura adequada para receber os turistas.

No entanto as respostas das entrevistas do presente estudo demonstram que a gestão carece de mais informações, como por exemplo a adaptação dos documentos técnicos (artigos e planos de manejo) para os colaboradores e usuários das UC's. Mais pesquisas científicas relacionadas à geodiversidade (como geoturísticas) poderiam ser solicitadas pelos órgãos gestores às universidades e grupos de trabalho de Conselhos Consultivos e Geoparque do Quadrilátero Ferrífero. Assim como a capacitação de guias de turismo quanto ao geoturismo, conforme observado por Boggiani (2018), e comprovado por Jacobi, Fleury e Rocha (2004, p. 1) no PESRM "a importância de visitas guiadas para melhor rendimento da atividade, e a valiosa ferramenta que as UC's representam no processo da construção do conhecimento ecológico e ambiental".

Nos parques amostrados reverbera a questão central do parque mundial pioneiro (de Yellowstone): a proteção dos recursos naturais diante da industrialização-urbanização. Contudo a relação da categoria do SNUC com a 
da União Internacional para a Conservação da Natureza (IUCN, 2008), parques e II respectivamente, se assemelha aos resultados observados por Pelizzaro et al. (2015, p. 31): os parques "serem manejados conforme diretrizes da V (Paisagem Terrestre/ Marinha Protegida)", que se aproxima mais do grupo de uso sustentável que de proteção integral.

Eagles, McCool e Haynes (2002, p. 88) apresentam como uma das estratégias e táticas para gerenciar altos níveis de uso de áreas protegidas, modificar o tipo de uso e tipo de visitante, como desencorajar ou banir práticas prejudiciais. Um exemplo pode ser o de estimular a interpretação e importância de um tipo de rocha ou mineral por meio de um $Q R$ Code virtual explicativo ao apontar o celular, invés da coleta de um suvenir natural.

Esta é uma solução que integra o geoturismo com o ecoturismo enquanto produto ratificando resultados de Bento, Farias e Nascimento (2020) - a serem ofertado pelos gestores dos parques, valorizando a geodiversidade e a biodiversidade como partes interdependentes dos geoecossistemas. Sendo "necessários meios interpretativos voltados para a interpretação do patrimônio geológico, meios que também poderão ser utilizados em atividades voltadas para o ecoturismo e para o geoturismo", conforme exposto por Moreira (2014, p. 24).

O próprio Ministério do Turismo (MTUR, 2010, p. 29-30) aponta atividades praticadas pelo ecoturismo que têm relação com o geoturismo, como: "observação de formações geológicas", "visitas a cavernas" e "trilhas interpretativas". Neste olhar, o geoturismo pode contribuir para alcançar as bases do ecoturismo enquanto

segmento da atividade turística que utiliza, de forma sustentável, o patrimônio natural e cultural, incentiva sua conservação e busca a formação de uma consciência ambientalista por meio da interpretação do ambiente, promovendo o bem-estar das populações. (MTUR, 2010, p. 17)

Por fim Coutinho et al. (2019, p. 765) corroboram a interface geoturismo-ecoturismo:

Os benefícios locais remetem ao envolvimento das comunidades locais em todo o processo, desde a gestão da localidade para o geoturismo até o fornecimento de serviços que promovem a geração de emprego e renda. Este envolvimento não apenas beneficia a comunidade e o meio ambiente, mas impacta na qualidade da experiência turística.

Assim, princípios do geoturismo (e do ecoturismo) como formação de uma consciência ambiental por meio da interpretação, apontam compromissos com a conservação ambiental. O que é buscado tanto pelos parques quanto pelos seus gestores.

\section{CONCLUSÕES}

A gestão da geodiversidade, seja em áreas protegidas como parques seja em geoparques não é uma tarefa fácil. Invés de, no fundo, ser, em parte, uma temática debatida por filósofos e religiosos na Antiguidade vem sendo reforçada com o surgimento da Geologia enquanto ciência e o Geoturismo como viagens de campo em fins do séc. XIX na Europa. Após o impacto da industrialização e urbanização na natureza emergiu à superfície como área de estudo em fins do séc. XX.

Se por um lado os turistas se impressionam com montanhas, cânions, cachoeiras e outros atrativos naturais, também se mostram curiosos quanto à formação dos mesmos. Para que mais pessoas continuem tendo acesso ao geoturismo é preciso, no entanto, conservá-los. Considerando esta oferta (atrativos) e esta demanda (visitantes) o geoturismo vem se consolidando como segmento turístico. Eis o desafio dos gestores: integrar visitação e conservação pelo manejo.

Os estudos de caso aqui apresentados, somados à literatura de temática, parques e geoparques afins demonstraram a percepção dos gestores para o geoturismo. Nota-se que a área de estudo (Quadrilátero Ferrífero e Serra do Espinhaço), ricas em biodiversidade, geodiversidade, e áreas naturais protegidas, têm uma moeda de duas faces: uma o apelo cênico da paisagem para o ecoturismo (em especial o ecológico); e outra vetores de pressão de uso e ocupação do solo (grandes centros urbanos e mineração). Destaca-se a necessidade do desenvolvimento do geoturismo tanto por pesquisadores (procurando entende-lo melhor) quanto a difusão do seu conhecimento (aplicação pelos órgãos gestores das UC's).

Os resultados demonstram a importância da interdisciplinaridade no estudo das UC's, cujo turismo não se dá somente com a oferta de atrativos pelos gestores públicos e privados, mas também pelo entendimento de sua demanda, ou 
seja, (geo)turistas e a comunidade receptora. O presente trabalho soma, assim, aos outros trabalhos publicados de oferta e de demanda geoturísticas, com o diferencial de ser um importante registro oral para ações de geoconservação. Tipo de conservação esta que Sharples (2002) considera crucial para a manutenção da biodiversidade e também como valor em si, independente dos recursos bióticos.

No entanto, abre-se uma janela de oportunidades para um cenário tal qual uma paisagem retratada por pintores naturalistas. Espera-se que este estudo sirva de forma mais contundente ao ICMBIO e IEF para que não sejam "parques de papel" quanto à geodiversidade, buscando essa efetividade de gestão com auxílio do geoturismo, cuja interpretação das características e processos geológicos, geomorfológicos, pedológicos e demais do patrimônio natural colabora (in)diretamente para a educação ambiental, e consequentemente a conservação.

\section{REFERÊNCIAS}

ALVES, R. F.; REZENDE, J. L. P.; BORGES, L. A. C.; FONTES, M. A. L.; ALVES, L. W. R. Perfil e percepção dos chefes de unidades de conservação do Sistema Estadual de Áreas Protegidas em Minas Gerais. Sociedade \& Natureza, v. 23, n. 2, p. 345-360, 2011 http://dx.doi.org/10.1590/S198245132011000200016.

BABBIE, E. Métodos de pesquisa de survey. Belo Horizonte: Ed. da UFMG, 2003.

BARDIN, L. Análise de conteúdo. Lisboa: Edições 70, 1999.

BENTO, L. C. M., FARIAS, M. F.; NASCIMENTO, M. A. L. Geoturismo: um segmento turístico? Turismo: Estudos \& Práticas (UERN), v. 9, n. 1, p. 1-23, 2020. Disponível em: $<$ http://natal.uern.br/periodicos/index.php/RT EP/article/view/653/557>. Acesso em: 28 ago. 2020.

BOGGIANI, P. C. A importância dos condutores de visitantes na divulgação das Geociências em unidades de conservação. Terrae Didática, v. $14, \quad$ n. $4, \quad$ p. $463-466,2018$. https://doi.org/10.20396/td.v14i4.8654197

BRASIL. Constituição da República Federativa do Brasil de 1988. Brasília: Governo Federal, 1988. Disponível em: <http://www.planalto.gov.br/ccivil_03/constitu icao/constituicao.htm>. Acesso em: 28 ago. 2020.
BRASIL. Lei no 9.985. Lei do SNUC. Brasília: Ministério do Meio Ambiente, 2000. Disponível em:

$<$ http://www.planalto.gov.br/ccivil_03/leis/L99

85.htm >. Acesso em: 28 ago. 2020.

BRILHA, J. B. R. Patrimônio geológico e geoconservação: a conservação da natureza na sua vertente geológica. São Paulo: Palimage editora, 2005.

BRITO, A. L. de. A geodiversidade na Unidade de Conservação do Parque Nacional da Serra do Cipó (MG). Revista Espinhaço, v. 4, n. 2, p. 25-32, 2017. Disponível em: $<$ http://www.revistaespinhaco.com/index.php/j ournal/issue/view/7>. Acesso em: 28 ago. 2020.

BUCKLEY, R. Environmental inputs and outputs in ecotourism: Geotourism with a positive triple bottom line? Journal of Ecotourism, v. 2, n. 1, p. 76-82, 2003. https://doi.org/10.1080/14724040308668135

BUCKLEY, R; PICKERING, C.; WEAVER, D. B. Nature-based Tourism. Environment and Land Management. London: CABI, 2003. https://doi.org/10.1079/9780851997322.0000

CARRERAS, J.; DRUGUET, E. Patrimonio geológico, una parte esencial en la gestión integral del patrimonio cultural en espacios protegidos. In: BARETTINO, D., WIMBLEDON, W. A. P.; GALLEGO, E. (Eds.) Patrimonio Geológico: Conservación y Gestión. Madrid: Instituto Tecnológico Geominero de España, 1999, p. 101-118.

CASTRO, P. T. A.; RUCHKYS, U. A. Iniciativas sobre patrimônio geológico e temas correlatos no Quadrilátero Ferrífero, MG. Caderno de Geografia, v. 27, Número Especial, p. 314331, 2017. https://doi.org/10.5752/P.23182962.2017v27nesp2p314

CHEN, A.; LU, Y.; NY, Y. C. Y. Principles of geotourism. Amsterdam: Springer, 2015. https://doi.org/10.1007/978-3-662-46697-1

COUTINHO, A. C. A, URANO, D. G., MATE, A. J.; NASCIMENTO, M. A. L. Turismo e Geoturismo: uma problemática conceitual. Rosa dos Ventos - Turismo e Hospitalidade, v. 11, n. 4, p. 754-772, 2019. http://dx.doi.org/10.18226/21789061.v11i4p75 4

CROFTS, R.; GORDON, J. E. Geoconservation in protected areas. In: WORBOYS, G. L., LOCKWOOD, M., KOTHARI, A., FEARY, S.; PULSFORD, I. (Eds.) Protected area governance and management. Canberra: ANU Press, 2015, p. 531-568.

DIGNE. Carta de Digne. Digne-Les-Bains: I Symposium Convention sur la Protection du Patrimoine Géologique, 1991. Disponível em: 
<http://www.progeo.pt/pdfs/direitos.pdf>.

Acesso em: 2 set. 2020.

DRUMMOND, G. M.; MARTINS, C. S.; MACHADO, A. B. M.; SEBAIO, F. A.; ANTONINI, Y. Biodiversidade em Minas Gerais: um atlas para sua conservação. Belo Horizonte: Fundação Biodiversitas, 2005. Disponível

<http://www.biodiversitas.org.br/atlas/>.

Acesso em: 28 ago. 2020.

EAGLES, P. F. J.; MCCOOL, S. F.; HAYNES, C. D. Sustainable Tourism in Protected Areas. Guidelines for planning and management. Gland, Switzerland: IUCN, 2002. Disponível em: <https://portals.iucn.org/library/sites/library/fi les/documents/PAG-008.pdf>. Acesso em: 28 ago. 2020.

EISENLOHR, P. V., MEYER, L., MIRANDA, P. L. S., REZENDE, V. L., DIAS E SARMENTO, C., MOTA, T. J. R. C., GARCIA, L. C.; MELO, M. M. R. F. Trilhas e seu papel ecológico: o que temos aprendido e quais as perspectivas para a restauração de ecossistemas? Hoehnea, v. 40, n. 3, p. 407-418, 2013. https://doi.org/10.1590/S2236-

89062013000300002

FARSANI, N. T.; COElHO, C.; COSTA, C. Geoparks as Art Museums for Geotourists. Revista Turismo e Desenvolvimento, n. 13, p. 173-182, 2010. Disponível em: <https://www.ua.pt/ReadObject.aspx?obj=303 $76>$. Acesso em: 28 ago. 2020.

FERREIRA, B. M.; LIMA, C. V. de; CANDEIRO, C. R. dos A. Geodiversity Geological And Geomorphological of the Municipality of Paraúna, Central-Southern Goiás State, Brazil. Sociedade \& Natureza, v. 32, p. 586600, 2020. https://doi.org/10.14393/SN-v322020-47312ago. 2020.

FONSECA FILHO, R. E; MOREIRA, J. C. O perfil do geoturista do Parque Estadual do Itacolomi, Ouro Preto e Mariana (MG). Revista Espacios (Caracas), v. 38, n. 47, p. 1-18, 2017. Disponível em: <http://www.revistaespacios.com/a17v38n47/a 17v38n47p18.pdf>. Acesso em: 27 ago. 2020.

FONSECA FILHO, R. E. Patrimônio pedológico e fatores impactantes ambientais nas trilhas de uso público em parques do Espinhaço Meridional. Tese (Doutorado em Ciências Naturais) - Ouro Preto: UFOP, 2017. Disponível em: <https://www.repositorio.ufop.br/bitstream/12 3456789/11421/1/TESE_Patrim\%C3\%B4nioPe dol\%C3\%B3gicoFatores.pdf $>$. Acesso em: 27 ago, 2020.

FONSECA FILHO, R. E; CASTRO, P. T. A.;
VARAJÃO, A. F. D. C.; FIGUEIREDO, M. A. Percepção dos visitantes do Parque Nacional da Serra do Cipó (MG) para o geoturismo. Anuário do Instituto de Geociências UFRJ, v. 41, n. 2, p. 520-537, 2018. http://dx.doi.org/10.11137/2018_2_520_537.

Disponível em: $<$ http://www.ppegeo.igc.usp.br/index.php/anig eo/article/view/13011/12605> . Acesso em: 27 ago. 2020.

FONSECA FILHO, R. E; CASTRO, P. T. A.; VARAJÃO, A. F. D. C.; FIGUEIREDO, M. A. Geoturismo e sítios pedológicos em trilhas dos Parques Estaduais do Itacolomi e Serra do Rola-Moça/MG. Revista Iberoamericana de Turismo, v. 9, n. 2, p. 105-117, 2019. https://doi.org/10.2436/20.8070.01.155.

FONSECA FILHO, R. E; RIBEIRO, G. S. Perfil do geoturista do Parque Estadual da Serra do Rola-Moça (MG). Revista Brasileira de Ecoturismo, v. 9, n. 3, p. 471-496, 2016. https://doi.org/10.34024/rbecotur.2016.v9.6539 GESTOR PEIT. Entrevista. Entrevistador: Ricardo Eustáquio Fonseca Filho. Ouro Preto (MG): UFOP, 75 min, Mp3, jan. 2017.

GESTOR PESRM. Entrevista. Entrevistador: Ricardo Eustáquio Fonseca Filho. Nova Lima (MG): UFOP, 54 min, Mp3, dez. 2016.

GESTOR PNSC. Entrevista. Entrevistador: Ricardo Eustáquio Fonseca Filho. Santana do Riacho (MG): UFOP, 24 min, Google Forms, mar. 2017.

GORDON, J. E., CROFTS, R., DÍAZMARTÍNEZ, E.; WOO, K. S. Enhancing the role of geoconservation in protected area management and nature conservation. Geoheritage, v. 10, p. 191-203, 2018. http://doi.org/10.1007/s12371-017-0240-5

GRAY, M. Geodiversity: valuing and conservating abiotic nature. London: John Wiley \& Sons, 2004. Disponível em: $<$ https://geoduma.files.wordpress.com/2010/02 /geodiversity.pdf>. Acesso em: 27 ago. 2020.

HOSE, T. A. Selling the story of Britain's stone. Environmental Interpretation, v. 10, n. 2, p. 16-17, 1995.

HOSE, T. A. (Ed.) Appreciating Physical Landscapes: Three Hundred Years of Geotourism. Geological Society, London, Special Publications, v. 417, p. 1-22, 2016. https://doi.org/10.1144/SP417.15

ICMBIO. Plano de Manejo da Área de Proteção Ambiental Morro da Pedreira e do Parque Nacional da Serra do Cipó. Brasília: Instituto Chico Mendes de Conservação da Biodiversidade, 2009.

ICMBIO. Cardápio de atrativos. Disponível em: 
<https://www1.icmbio.gov.br/parnaserradocip o/images/stories/guia_do_visitante/Cardapio_ FINAL.pdf >. Acesso em: 29 ago. 2020.

IEF. Plano de manejo do Parque Estadual do Itacolomi. Belo Horizonte: Instituto Estadual de Florestas, 2007a.

IEF. Plano de manejo do Parque Estadual da Serra do Rola-Moça, incluindo a Estação Ecológica de Fechos. Belo Horizonte: Instituto Estadual de Florestas, 2007b.

IUCN. Guidelines for applying protected area management categories. Gland: International Union for Conservation of Nature, 2008. Disponível em: <https://portals.iucn.org/library/sites/library/fi les/documents/PAG-021.pdf>. Acesso em: 28 ago. 2020.

JACOBI, C. M., FLEURY, L. C.; ROCHA, A. C. C. L. Percepção ambiental em unidades de conservação: experiência com diferentes grupos etários no Parque Estadual da Serra do Rola Moça, MG. Anais do $2^{\circ}$ Congresso Brasileiro de Extensão Universitária, Belo Horizonte, 2004. Disponível em: <https://www.ufmg.br/congrext/Meio/Meio12. pdf $>$. Acesso em: 28 ago. 2020.

LIMA, G. S., RIBEIRO, G. A.; GONÇALVES, W. Avaliação da efetividade de manejo das unidades de conservação de proteção integral em Minas Gerais. Revista Árvore, v. 29, n. 4, p. 647-653, 2005. https://doi.org/10.1590/S0100-

67622005000400017

MACHADO, M. F.; SILVA, S. F. da. Geodiversidade do estado de Minas Gerais. Belo Horizonte: CPRM, 2010. Disponível em: <http://rigeo.cprm.gov.br/xmlui/bitstream/han dle/doc/16735/Geodiversidade_MG.pdf?sequen ce=1\&isAllowed=y>. Acesso em: 28 ago. 2020 .

MANTESSO NETO, V., MANSUR, K. L., RUCHKYS, U.; NASCIMENTO, M. A. L. O que há de geológico nos atrativos turísticos convencionais no Brasil. Anuário do Instituto de Geociências - UFRJ, v. 35, n. $1, \quad$ p. $\quad 49-57, \quad 2012$. http://dx.doi.org/10.11137/2012_1_49_57

MEDEIROS, C. A. F., GOMES, C. S. C. D.; NASCIMENTO, M. A. L. Gestão em Geoparques: desafios e realidades. Revista Brasileira de Pesquisa em Turismo, v. 9, n. 2, p. 342-359, 2015 . https://doi.org/10.7784/rbtur.v9i2.798

MEIRA, S. A, NASCIMENTO, M. A. L.; SILVA, E. V. Unidades de conservação e geodiversidade: uma breve discussão. Terr@ Plural, v. 12, n. 2, p. 166-187, 2018. http://doi.org/

10.5212/TerraPlural.v.12i2.0002

MMA. Gestão Participativa do SNUC. Brasília: Ministério do Meio Ambiente, 2004.

MOREIRA, J. C. Geoturismo e interpretação ambiental. Ponta Grossa, PR: Ed. UEPG, 2014.https://doi.org/10.7476/9788577982134

MOREIRA, J. C. Geoturismo: uma abordagem histórico-conceitual. Turismo e Paisagens Cársticas, v. 3, n. 1, p. 5-10, 2010.

MTUR. Ecoturismo. Orientações básicas. Brasília: Ministério do Turismo, 2010. Disponível em: <http://www.turismo.gov.br/sites/default/turis mo/o_ministerio/publicacoes/downloads_publi cacoes/Ecoturismo_Versxo_Final_IMPRESSx O_.pdf>. Acesso em: 28 ago. 2020.

MUNHOZ, E.A.P.; LOBO, H.A.S. Proteção e conservação da geodiversidade na legislação brasileira. Geonomos, v. 26, n. 1, p. 21-30, 2018.

https://doi.org/10.18285/geonomos.v26i1.1236

NEWSOME, D., DOWLING, R.; LEUNG, Y-F. The nature and management of geotourism: A case study of two established iconic geotourism destinations. Tourism Management Perspectives, v. 2, n. 3, p. 19-27, 2012. https://doi.org/10.1016/j.tmp.2011.12.009

OBSERVATÓRIO DE TURISMO DE MINAS GERAIS. Pesquisa de Demanda Turística Minas Gerais. Alta e Baixa Temporada 2017. Belo Horizonte: Secretaria de Estado de Turismo de Minas Gerais, 2017. Disponível em:

<https://www.dropbox.com/s/yfcuq62oq0sywq d/Apresenta\%C3\%A7\%C3\%A30\%20-\%20Cons olidado.pdf?dl=0>. Acesso em: 28 ago. 2020.

ONARY-ALVES, S. Y.; BECKER-KERBER, B.; VALENTIN, P, R.; PACHECO, M. L. A. F. O conceito de geoparque no Brasil: reflexões, perspectivas e propostas de divulgação. Terræ Didática, v. 11, n. 2, p. 94-107, 2015. https://doi.org/10.20396/td.v11i2.8640712OS

ANELLO, M. C. P.; DANDERFER, A.; CASTRO, P. T. A. Caracterização de lugares de interesse geológico e trilhas geoturísticas no Parque Estadual do Itacolomi - Ouro Preto e Mariana, Minas Gerais. Geociências UNESP, v. 32, n. 2, p. 286-297, 2013. Disponível em: <http://www.ppegeo.igc.usp.br/index.php/GEO $\mathrm{SP} /$ article/download/7306/6750>. Acesso em: 28 ago. 2020.

PELIZZARO, P. C.; HARDT, L. P. A.; HARDT, C.; HARDT, M.; SEHLI, D. A. Gestão e manejo de áreas naturais protegidas: contexto internacional. Ambiente \& Sociedade, v. XVIII, n. 1, p. 21-40, 2015. Disponível em: <https://www.scielo.br/pdf/asoc/v18n1/pt_1414 
-753X-asoc-18-01-00019.pdf>. Acesso em: 28 ago. 2020.

PEREIRA, E. O.; AZEVEDO, U. R.; ONDICOL, R. P. Modelagem da geodiversidade da Área de Proteção Ambiental Sul da Região Metropolitana de Belo Horizonte - MG. Geonomos, v. 21, n. 2, p. 97-101, 2013. Disponível em: <https://periodicos.ufmg.br/index.php/revistag eonomos/article/view/11744/8484>. Acesso em: 28 ago. 2020.

PEREIRA, L. S. 10 anos da pesquisa em geoturismo no Brasil: balanços e perspectivas. Geografias, v. 14, n. 1, p. 106-117, 2017. Disponível em: <https://periodicos.ufmg.br/index.php/geografi as/article/view/13438/10669>. Acesso em: 28 ago. 2020.

REIS, D. L. R. A geodiversidade do Parque Estadual Serra do Rola Moça, Minas Gerais. Anais do XVIII Simpósio Brasileiro de Sensoriamento Remoto, 2017, p. 128-133. Disponível em: <https://proceedings.science/proceedings/59/_p apers/61646/download/abstract_file1>. Acesso em: 28 ago. 2020.

REYNARD, E.; BRILHA J. (Eds.) Geoheritage: assessment, protection and management. Amsterdam: $\quad$ Elsevier, 2018. https://doi.org/10.1016/B978-0-12-8095317.00030-7

REZENDE, J. L. P., ALVES, R. G., BORGES, L. A. C., FONTES, M. A. L.; ALVES, L. W. R. Avaliação da gestão das UC do Sistema Estadual de Áreas Protegidas de Minas Gerais. GEOGRAFIAS, v. 6, n. 1, p. 87-106, 2010. Disponível em: <https://periodicos.ufmg.br/index.php/geografi as/article/view/13285/10517 >. Acesso em: 28 ago. 2020.

SANTOS, N. B. dos. Efetividade dos planos de manejo na gestão de parques estaduais de Minas Gerais. Dissertação (Mestrado em Ecologia, Conservação e Manejo da Vida Silvestre) - Belo Horizonte: UFMG, 2016. Disponível em: <https://repositorio.ufmg.br/bitstream/1843/B UBD-

A9MHCK/1/dissertacao_natalia_britto_final.p df>. Acesso em: 28 ago. 2020.

SHARPLES, C. Concepts and principles of geoconservation. Hobart, Australia: Tasmanian Parks \& Wildlife, 2002.

SOUSA, E. N., RODRIGUES, L. M.; TOMAZZONI, E. L. Análise de Conteúdo: uma revisão preliminar dos seus domínios de aplicação em investigações turísticas. Anais do Seminário da ANPTUR, 2016. Disponível em: <https://www.anptur.org.br/anais/anais/files/1 3/572.pdf >. Acesso em: 28 ago. 2020.

ŚWIERKOSZ, K., KOŹMA, J., RECZYŃSKA, K.; HALAMA, M. Muskau Arch Geopark in Poland (Central Europe) - Is it possible to integrate geoconservation and geoeducation into biodiversity conservation? Geoheritage, v. $9, \quad$ p. $\quad 59-69, \quad 2017$. https://doi.org/10.1007/s12371-016-0178-z

TOYAMA, D.; MENEZES, D. B.; MENDONÇA, I. R.; CAPOIA, E. F.; FAGUNDES, J. G. Parque urbano e geoconservação: o caso do Parque do Bicão, São Carlos - São Paulo, Brasil. Sociedade \& Natureza, Uberlândia, v. $30, \quad$ n. $1, \quad$ p. $255-276,2018$. http://dx.doi.org/10.14393/SN-v30n1-2018-11$\mathrm{X}$

UNESCO. Unesco Global Geoparks. Disponível em:

<http://www.unesco.org/new/en/naturalsciences/environment/earth-sciences/unescoglobal-geoparks/frequently-askedquestions/what-is-a-unesco-global-geopark/>. Acesso em: 2 set. 2020.

VIEIRA, L. F. S.; VERDUM, R. A proteção da natureza e do patrimônio da humanidade pela beleza cênica da paisagem. Confins Revista Franco-Brasileira de Geografia, v. 40, n. 40, p. 1-18, 2019. https://doi.org/10.4000/confins.19680

WHITEHEAD, A. N. The concept of Nature. (1920) 2006. Disponível em: $<$ https://archives.library.illinois.edu/erec/Univ ersity\%20Archives/1515022/OriginalFiles/LIT ERATURE/WHITEHEAD/Concept $\% 20$ of $\% 20$ Nature\%20Whitehead.pdf $>$. Acesso em: 27 ago, 2020.

WWF. Avaliação da gestão de unidades de conservação: métodos RAPPAM (2015) e SAMGE (2016). Brasília: WWF, 2017. Disponível em: <https:/www.icmbio.gov.br/portal/images/stor ies/DMAG/avaliacao_da_gestao_das_ucs_rap pam_2015_samge_2016_.pdf>. Acesso em: 28 ago. 2020. 